\title{
LA FORMACIÓN EN PSICOLOGÍA DESDE UNA PERSPECTIVA DE COMPETENCIAS. UNA CONTRIBUCIÓN PARA EL MEJORAMIENTO DE LA FORMACIÓN UNIVERSITARIA EN CHILE
}

\author{
Piedad Cabrera, Antonia Larraín, Renato Moretti, \\ Mauricio Arteaga, M. Alejandra Energici ${ }^{1}$
}

\begin{abstract}
RESUMEN
Este artículo presenta una investigación cuyo objetivo fue levantar las competencias que, según la comunidad académica de la Facultad de Psicología de la Universidad Alberto Hurtado (UAH), y profesionales de la psicología, corresponde garantizar en la formación de pregrado. Éste fue un punto de partida para un trabajo de mejoramiento de la formación que continúa hasta hoy. La investigación se compone de tres estudios enlazados. En los resultados se desprende cierta configuración de competencias entendida como nuclear para la formación de los psicólogos, junto con cuestiones de interés para la reflexión sobre la formación. Se destacan las diferencias existentes entre los actores acerca de qué competencias son más relevantes. Se discuten las implicancias de estos resultados para la noción de competencias y la equidad en la formación en psicología.
\end{abstract}

Palabras clave: psicología, competencias, calidad y equidad, educación superior.

\section{PSYCHOLOGY UNDERGRADUATE EDUCATION FROM THE PERSPECTIVE OF COMPETENCES: AN EFFORT TO IMPROVE THE CHILEAN UNIVERSITY EDUCATION}

\begin{abstract}
This paper presents a research aimed to suggest which competences students have to develop during their undergraduate training in psychology according to the Psychology School academic community from Universidad Alberto Hurtado and professional psychologists in general. It consists of three studies. Findings suggest some specific competences critical to psychology education. There are some coincidences in considerations teachers, students and professionals have regarding to those competences in psychology professional practice and also differences which represent an interesting diversity of expectations. The paper also discusses the implications of these results for psychology education equity and the notion of competence.
\end{abstract}

Key words: psychology, competences, higher education, quality and equity.

1 Universidad Alberto Hurtado, Chile. Contacto: alarrain@uahurtado.cl

* La investigación que se reporta en este artículo fue cofinanciada por los Fondos Internos de Investigación de la Universidad Alberto Hurtado y por la Facultad de Psicología de la misma universidad. La preparación del artículo fue posible gracias al apoyo de la Facultad de Psicología de la Universidad Alberto Hurtado. 


\section{LA FORMACIÓN EN PSICOLOGÍA DESDE UNA PERSPECTIVA DE COMPETENCIAS. \\ UNA CONTRIBUCIÓN PARA EL MEJORAMIENTO DE LA FORMACIÓN UNIVERSITARIA EN CHILE}

\section{Introducción}

La educación superior en Chile ha sufrido cambios importantes en los últimos 30 años. Los cambios más relevantes tuvieron efecto con las reformas legales de 1981 y 1989, las que impactaron en la generación de un gran número de instituciones de educación superior, una progresiva masificación del acceso a la educación terciaria, y el establecimiento de un sistema de educación superior profundamente diversificado (Aedo y González, 2004).

Las políticas aplicadas desde 1981 han configurado un sistema de educación superior cuya cobertura se ha incrementado de manera constante permitiendo el acceso a grupos de la población que antes no participaban en este tipo de educación (Brunner, 2009; Espinoza y González, 2008). En cifras absolutas, mientras que en 1983 había 172.995 matriculados en pregrado, en 1993 el número llegó a 310.132; en 2003 a 542.516, y en 2009 a 835.247 estudiantes (SIES, 2010).

No obstante lo anterior, sería impreciso decir que el acceso a las instituciones de educación superior es equitativo entre los diferentes niveles socioeconómicos (OCDE y BIRD/Banco Mundial, 2009). De hecho, según Espinoza y González (2008) mientras la variación de la cobertura de educación superior en la población de 18 a 24 años entre el año 1990 y el año 2003 en el quintil de la población más rico alcanzó a 73,6\%, en el quintil más pobre sólo llegó al 14,7\%.

Adicionalmente a la inequidad en el acceso a la educación terciaria, y producto de las consecutivas transformaciones sufridas por el sistema desde los años 80 y de su interacción con un sistema 
escolar que, según García-Huidobro (2004), es profundamente segmentado e inequitativo, actualmente la mayoría de los estudiantes que entra a las universidades más reputadas lo hace como producto de su capital social y cultural. Si consideramos que las universidades más prestigiosas coinciden, según Brunner (2009) en gran medida con aquéllas más selectivas, el resultado es un sistema de educación superior que tiende a reproducir la inequidad y segmentación propia del sistema escolar. En esta línea, la mayoría de los estudiantes que entra a las universidades más prestigiosas y selectivas del sistema lo hace como efecto de, en términos de Bourdieu y Passeron (1964/2003), importantes desigualdades sociales que se reflejan en privilegios culturales. Siguiendo a estos autores, la representación de las capas sociales en la enseñanza superior es sólo un reflejo parcial de la desigualdad educativa, y aunque la educación superior se haga más accesible, ello no implica que el ingreso a la educación postsecundaria, por sí mismo, permita la adquisición efectiva de las competencias profesionales y académicas socialmente deseables y exigibles para todos los egresados.

Brunner (2009) observa que el proceso de acceso altamente selectivo de ciertas universidades, favorece la reputación de las mismas toda vez que los estudiantes "quienes compran el servicio proporcionan a la institución, al mismo tiempo, un insumo fundamental de su proceso de producción bajo la forma de efecto entre pares" (p. 378). Es decir, mientras las universidades altamente selectivas pueden trabajar con el supuesto de la preparación académica de sus estudiantes, las universidades poco selectivas tienen pocas probabilidades de contar tanto con estudiantes de alta preparación académica como con los beneficios del efecto pares ${ }^{2}$. Cabe notar el alcance de esta forma de segmentación educativa, señalando que entre las universidades menos selectivas en el año 2007 había 30 instituciones privadas, las cuales tuvieron en conjunto una participación del 48,8\% de la matrícula nueva total nacional (Brunner, 2009).

2 La mejora de los procesos y logros educativos de un estudiante, consecuencia de las características de sus pares. Aunque es un aspecto discutido, hay evidencia para declarar que el efecto pares tiene una rol significativo en el progreso educativo de los estudiantes menos aventajados (Goethals, Winston y Zimmerman, 1999; Zimmer y Toma, 2000; Hanushek, Kain, John, Markman y Rivkin, 2003; Valenzuela, Bellei y De los Ríos, 2008). 
Si bien las universidades más selectivas se diferencian por el tipo de estudiantes que atienden, no es clara la magnitud del valor agregado que estas instituciones entregan a los estudiantes por año de formación. La investigación sobre la relación entre selectividad y calidad de la formación de pregrado en Estados Unidos muestra una relación débil y trivial entre la selectividad de las instituciones que imparten formación de pregrado (college) y la calidad de los aprendizajes y el desarrollo cognitivo de los estudiantes durante su formación (ver por ejemplo, Anaya, 1996; Astin, 1968; Flowers, Osterlind, Pascarella, y Pierson, 2001; Knox, Lindsay y Kolb, 1992; Toutkoushian y Smart, 2001). Una investigación de Pascarella, Cruce, Umbach et al. (2006), cuyo objetivo fue estimar la relación entre el impacto de la selectividad de carreras de pregrado y las experiencias de "buenas prácticas" de educación superior según la percepción de los estudiantes, no encontró relaciones substanciales entre ambas variables. Los autores concluyen que estudiar en una institución selectiva no asegura que el estudiante participe de experiencias determinantes en su desarrollo cognitivo.

Lo anterior sugiere que es importante avanzar en la evaluación y mejoramiento del valor agregado que entrega la formación de pregrado, por sobre las características de entrada de los estudiantes. Esto es crucial, pues al recibir a un estudiante cualquier institución debe cumplir el compromiso (imperativo) de prepararlo para el mercado laboral de manera competente. Se hace necesario profundizar los esfuerzos para garantizar que los estudiantes con condiciones de entrada vulnerables sean capaces de avanzar, académica y profesionalmente, más allá de lo que su origen social o su formación escolar hubieran predicho. Desde el punto de vista de Bourdieu y Passeron (1964/2003), si la función del sistema de enseñanza superior es producir individuos selectos y comparables, es necesario introducir en la enseñanza la consideración de las desigualdades reales, a través de una pedagogía que tenga en cuenta los contenidos y los fines profesionales de la enseñanza y no olvide que las diferentes relaciones pedagógicas tendrán un rendimiento diferente según el origen social de los estudiantes. En otras palabras, estas universidades deben ser capaces de ofrecer una educación terciaria efectiva, análogamente a lo planteado por modelos 
desarrollados para comprender las dinámicas de la educación escolar (acerca de estos modelos léase Nuttal, Goldstein, Prosser y Rasbah, 1989; Reynolds y Cuttance, 1992; Arancibia, 1992; Murillo, 2003; Carrasco, 2008).

La pregunta fundamental es cómo hacerlo. La preocupación por la calidad si bien está presente en las políticas a partir de los años 1990-1991 y se materializa con la puesta en marcha de los procesos de acreditación de la mano de la Comisión Nacional de Acreditación (CNA), aún es insuficiente. Por un lado, hasta ahora el sometimiento a la acreditación es voluntario y al año 2008 sólo el 21\% de la matrícula de educación universitaria de pregrado correspondía a instituciones dentro del proceso. Por otro lado, aunque como lo afirma Rodríguez Ponce (2008), los procesos de acreditación generan procesos de revisión de la educación impartida y planes de mejoramiento, la orientación técnica acerca de cómo avanzar en el mejoramiento de la calidad de los procesos de enseñanza y aprendizaje no está necesariamente disponible.

En un contexto en que los académicos y docentes, que no sólo son quienes imparten la docencia, sino que además tienen en sus manos la gestión pedagógica de las instituciones, no están particularmente preparados en estrategias pedagógicas y aprendizaje, la respuesta no es sencilla. Se requiere un trabajo en el mejoramiento de los procesos de enseñanza-aprendizaje, pero no siempre se cuenta con recursos humanos ni económicos para ello. Más aun, es necesario tener una visión global del proceso de formación y los fines de éste, pero además es importante observar cómo cada momento de currículum contribuye diferencial y progresivamente hacia ello. En otras palabras, una alternativa para trabajar en la calidad de la formación es identificar aquellas competencias de salida que los estudiantes deberían desplegar, para luego mirar el currículum y los diferentes cursos de manera de garantizar que la formación en su conjunto garantice estas competencias.

En este artículo se presenta una investigación cuyo objetivo fue levantar las competencias que, según la comunidad de la carrera de la Facultad de Psicología de la Universidad Alberto Hurtado (UAH), 
(estudiantes y profesores) y profesionales, deben garantizarse en la formación de pregrado. En esta línea, dicha investigación fue un punto de partida para un trabajo de mejoramiento que se continúa hasta hoy en la formación del futuro psicólogo. Ésta se compone de tres estudios íntimamente relacionados, los que se articulan para dar sustento a nuestra forma de pensar la formación en psicología. A continuación se discuten los antecedentes generales, luego se describe cada estudio y sus resultados para, finalmente, discutirlos en su conjunto.

\section{¿Qué competencias se deben garantizar en la formación de pregrado en psicología?}

Los trabajos a mayor escala en la línea de buscar convergencias y desarrollar lenguajes comunes en cualificaciones, procesos de formación, objetivos de aprendizaje y competencias se enmarcan en el proyecto Tuning. Este proyecto surge el año 2000 luego de la Declaración de Bologna de 1999, con el objetivo de contribuir a la elaboración de cualificaciones convergentes en distintas disciplinas y procesos de formación europeos. El modelo de trabajo tiene como punto de partida identificar perfiles de titulación, luego de lo cual se pasa a diseñar o revisar programas definiendo como primer paso resultados esperados de aprendizaje y competencias (González y Wagenaar, 2008). Las competencias son aquí entendidas como "una combinación dinámica de conocimientos, comprensión, habilidades y capacidades" (p.17) que se desarrollan en varias unidades de un curso y se evalúan en diferentes etapas.

Con respecto a estas últimas, el proyecto reconoce competencias genéricas que son comunes a diferentes áreas (Rial, 2006), y específicas o propias de cada área. Dentro de las genéricas distingue competencias instrumentales (habilidades cognitivas, metodológicas, tecnológicas y lingüísticas), interpersonales (habilidades sociales) y sistémicas (i.e. combinación de comprensiones).

En dicho proyecto, el modo de trabajo consistió en consultar a cuatro grupos (académicos, estudiantes, empleadores y graduados) acerca del grado de importancia y de realización de ciertas 
competencias. Partieron consultando las 27 competencias propuestas como genéricas (Beneitone, Esquetini, González, et al., 2007) y luego trabajaron el levantamiento de competencias de 28 áreas temáticas en Europa y 12 en América Latina. En Chile sólo se trabajó en las áreas de Matemáticas, Historia, Educación y Administración de Empresas (Muñoz y Sobrero, 2006; Beneitone, Esquetini, González et al., 2007). En psicología, por tanto, no ha habido un levantamiento de competencias específicas en el marco de este programa ni para Europa ni para Latinoamérica.

No obstante lo anterior, en el último tiempo hemos atendido a la aparición de trabajos que intentan discutir y/o levantar competencias específicas para la formación en psicología tanto en Chile como en Latinoamérica, ya sea por intereses al interior de las diferentes universidades (González, Gómez, Espinosa, et al., 2007; Sanhueza, 2008; Zanatta y Moysén, 2002; Bartram y Roe, 2005), o bien, por grupos o redes que trabajan en conjunto para definir las competencias propias según especialidad (Castro, 2004; Juliá, 2006).

En Chile, tanto el Departamento de Psicología de la Universidad Cardenal Silva Henríquez (2008) como la Universidad Adolfo Ibáñez (Sanhueza, 2008) han realizado trabajos para definir competencias claves para la formación en psicología, tanto a nivel general como a nivel de especialidades.

Los trabajos antes mencionados sirven como antecedentes, pero a la vez destacan la inexistencia de una discusión transversal, tanto internacional como nacional, con respecto a las competencias distintivas de todo psicólogo. Aunque desde el punto de vista de la evaluación de calidad no es posible tener un parámetro único (Rodríguez Ponce, 2008), la discusión acerca de competencias nucleares del psicólogo podría iluminar el sello particular que ofrece cada institución permitiendo ciertos parámetros comunes de calidad. 


\section{Características de la formación en psicología en la Universidad Alberto Hurtado}

En el año 2001 se crearon simultáneamente la Escuela (posteriormente, Facultad) y la carrera de Psicología de la Universidad Alberto Hurtado. La unidad académica se propuso cultivar, entre otras opciones formativas posibles en psicología, un sello distintivo caracterizado por la excelencia y la vocación social. En este sentido, el proyecto académico de la Facultad de Psicología (2007) es consistente con la misión de la universidad, aunque configura la existencia de desafíos propios a la formación en psicología en este contexto institucional. Particularmente resulta relevante el desafío de privilegiar el pluralismo de orígenes y modos de vida de los estudiantes de la carrera y, a la vez, aspirar a la excelencia académica y profesional. El desafío fundamental, entonces, corresponde al de articular ambas aspiraciones, generando las condiciones para el logro de aprendizajes de calidad en situaciones de alta heterogeneidad, y más aun, en palabras de Sebastian (2007), transformar esta diversidad en oportunidades de aprendizaje para todos.

Dado el problema general de la formación superior que motiva este texto, es relevante explorar las características generales de entrada de los estudiantes de la carrera. Un primer elemento apreciable es que la matrícula en esta carrera ha aumentado sostenidamente. Mientras que en el año 2005 la matrícula nueva fue de 57 estudiantes, en el año 2010 ésta fue de 103 estudiantes. Por otro lado, la matrícula por género se ha mantenido consistentemente en torno a un hombre por cada dos mujeres que acceden a la carrera ${ }^{3}$.

Con respecto a la composición de la matrícula según la dependencia de los establecimientos escolares de procedencia, en la tabla n. ${ }^{\circ} 1$ se observa que en el año 2005 un 40,4\% de los estudiantes señaló provenir de un colegio particular pagado; en cambio, el año 2010 el grupo de individuos que declaró lo mismo bajó a un 30,1\%.

3 Elaboración propia a partir de datos provistos por la Dirección de Aprendizaje Institucional de la Universidad Alberto Hurtado. 
Tabla n. ${ }^{\circ}$ 1. Dependencia de establecimiento escolar de origen de los estudiantes nuevos.

\begin{tabular}{|l|r|r|r|r|r|c|}
\hline & 2005 & 2006 & 2007 & 2008 & 2009 & 2010 \\
\hline No declara & $26,3 \%$ & $18,8 \%$ & $11,8 \%$ & $19,7 \%$ & $13,5 \%$ & $0,0 \%$ \\
\hline Municipal & $7,0 \%$ & $16,3 \%$ & $14,0 \%$ & $16,7 \%$ & $25,7 \%$ & $20,4 \%$ \\
\hline Particular pagado & $40,4 \%$ & $37,5 \%$ & $25,8 \%$ & $25,8 \%$ & $24,3 \%$ & $30,1 \%$ \\
\hline Particular subvencionado & $26,3 \%$ & $27,5 \%$ & $48,4 \%$ & $37,9 \%$ & $36,5 \%$ & $49,5 \%$ \\
\hline
\end{tabular}

Fuente: elaboración propia a partir de datos provistos por la Dirección de Aprendizaje Institucional de la Universidad Alberto Hurtado.

Como dato complementario, la amplia mayoría de los estudiantes señala que la modalidad educativa en su colegio de origen correspondió a científico-humanista, fluctuando entre un mínimo de $87,1 \%$ en 2007 y un máximo de $96,3 \%$ en 2006. Por otro lado, la mayor parte de la matrícula nueva ha correspondido a estudiantes que egresaron de enseñanza media durante los tres años inmediatamente anteriores al año de admisión en curso ${ }^{4}$.

Respecto a su rendimiento académico de entrada, la tabla $\mathrm{n} .^{\circ}$ 2 muestra los resultados de los estudiantes nuevos en la Prueba de Selección Universitaria. Se puede apreciar que el rendimiento inicial de los estudiantes ha tendido al alza, de 595,25 puntos promedio en 2005, a 618,624 puntos promedio en 2010. En todos los años, el puntaje promedio de la carrera es superior al promedio de la UAH.

Tabla n. ${ }^{\circ}$ 2. Rendimiento de la matrícula nueva de psicología en la Prueba de Selección Universitaria.

\begin{tabular}{|c|c|c|c|c|c|}
\hline $\begin{array}{c}\text { Año de } \\
\text { Admisión }\end{array}$ & $\begin{array}{c}\text { Prueba } \\
\text { Lenguaje }\end{array}$ & $\begin{array}{c}\text { Prueba } \\
\text { Matemáticas }\end{array}$ & $\begin{array}{c}\text { Promedio } \\
\text { PSU }\end{array}$ & $\begin{array}{c}\text { Promedio PSU } \\
\text { UAH }\end{array}$ & $\begin{array}{c}\text { Notas } \\
\text { Enseñanza } \\
\text { media }\end{array}$ \\
\hline 2005 & 617,16 & 573,33 & 595,25 & 558 & 575,92 \\
\hline 2006 & 628,39 & 575,41 & 602,15 & 565 & 599,58 \\
\hline 2007 & 630,94 & 581,01 & 606,43 & 568 & 595,11 \\
\hline 2008 & 630,16 & 584,22 & 607,19 & 578 & 588,98 \\
\hline 2009 & 637,80 & 598,28 & 617,80 & 586 & 589,7 \\
\hline 2010 & 646,86 & 590,36 & 618,89 & - & 581,66 \\
\hline
\end{tabular}

Fuente: elaboración propia a partir de datos provistos por la Dirección de Aprendizaje Institucional de la Universidad Alberto Hurtado.

4 Elaboración propia a partir de datos provistos por la Dirección de Aprendizaje Institucional de la Universidad Alberto Hurtado. 
En síntesis, cabe considerar a los estudiantes de psicología como un grupo que, dentro de la UAH, se encuentra en una posición más favorable que el promedio de los estudiantes. Sin embargo, respecto de su origen socioeducativo y de su rendimiento en la PSU, no se encuentra dentro los grupos de elite de la educación chilena. Además de ello, en la composición socioeducativa del estudiantado ha tendido a aumentar la representación de los segmentos de la educación subvencionada y, al mismo tiempo, se hacen presentes estudiantes que obtienen un mayor rendimiento académico en comparación con las cohortes anteriores y respecto de la media nacional.

\section{¿Por qué se habla de competencia?}

Antes de describir los estudios y sus respectivos resultados, es relevante detenerse en la noción de competencias. La primera cuestión es responder a la pregunta de por qué hablar de competencias. Esto es doblemente importante pues aunque, como afirma Jonnaert, Masciotra, Barrette, et al (2007), la noción de competencias es amplia y admite diferentes perspectivas, en la discusión de educación superior en Chile ha entrado muy de la mano con los intentos de algunas instituciones y disciplinas de "seguir" el proyecto Tuning, esto es, de elaborar un currículum "por" competencias. La implicación inevitable es cierta connotación de exceso de formalización y prescripción en el currículum y su gestión, sin claridad del aporte particular que tiene la noción de competencias. En este mismo contexto, la noción de competencias se relaciona con una visión tecnócrata de la formación profesional que enfatiza el saber hacer por sobre el saber (pensar).

Dicho lo anterior, se puede afirmar que hoy existe un amplio consenso, aunque no poca perplejidad, particularmente entre autores europeos como Perrenoud (1998), Jonnaert, Masciotra, Barrette, et al., (2007), Aguerrondo (2009) y Tobón (2007), acerca de que una competencia puede ser concebida como un proceso en el que se movilizan e integran diferentes recursos del individuo para hacer frente a una situación concreta y particular. Ahora bien, no obstante lo claro y simple que aparezca esta descripción, contiene una serie de dificultades para su comprensión y operativización. 
Primero que todo, lo que está detrás de esta definición es una imagen de individuo que "tiene" una serie de recursos elementales (como quien cuenta con diferentes alimentos en una despensa) que se ponen en movimiento conjuntamente para enfrentar una situación particular. Más allá de que existan argumentos clásicos en el ámbito de la psicología para discutir este punto (ver James, 1890/1981), lo relevante sería preguntarse: ¿Cómo, entonces, se "obtienen" estos elementos? ¿Cómo se podría entender la idea de aprender elementos de competencias primero y luego competencias? En un contexto en que lo que se intenta es ver la educación a través de las competencias, esto resulta a la vez complejo y relevante de responder.

Por otra parte, y ligado a la noción de situación, lo que estos autores enfatizan es que la competencia sólo existe asociada a una situación. Pero, ¿qué se entiende por situación? Lo primero es que situación es tratada intrínsecamente ligada a un problema que demanda una acción efectiva por parte del individuo. En el caso de la educación superior ésta debería ser entendida como una demanda profesional. En este sentido, situación se refiere por una parte a un evento concreto y real, y por otra, a un problema que habría que solucionar. En consecuencia, una competencia sólo puede ser definida cuando hay situaciones concretas que demandan cierto tipo de respuesta profesional.

Si se tiene en perspectiva el proceso de formación disciplinar, esto equivale a decir que las situaciones concretas particulares orientan la totalidad de la educación, y deben usarse desde un comienzo en ésta. Lo que se pierde de vista es justamente todas aquellas capacidades que sólo mediatamente tienen que ver con habilidades profesionales concretas, y que en sí mismas debieran ser entendidas como competencias, por ejemplo, ser capaz de comprender ciertos textos de Lev Vygotski, o ser capaz de pensar ciertos conceptos freudianos. La importancia de lo anterior no se juega necesariamente en ser capaz de usar los conceptos freudianos para efectos de una relación terapéutica, sino que se juega muchísimo antes en la misma capacidad de pensar a Freud, y en todo lo que en términos de capacidades generales de pensamiento se gana con realizar esto. ¿No sería una competencia comprender X texto de 
Freud? ¿No es una situación concreta verse enfrentado a explicar $\mathrm{X}$ concepto a la luz de Y concepto en una evaluación oral? ¿La competencia, entonces, se identifica sólo ahí donde se juega el valor en función de su utilidad técnica?

Dicho esto, y sin afán de exhaustividad sino a modo de ilustración de algunas perplejidades que están contenidas en la noción de competencia más difundida hoy en día en el ámbito de la educación, la investigación que se presenta a continuación toma como punto de partida la noción de competencias contenida en el proyecto Tuning y sus formulaciones, asumiendo que funciona como una noción de sentido común y un tipo de formulación simple (pero imprecisa) que permite preguntar e indagar en las creencias de los diferentes actores.

A continuación se presenta la investigación cuyo objetivo central fue levantar las competencias que según la comunidad local, es decir, estudiantes y profesores de la Facultad, y profesionales de la psicología, deben garantizarse en la formación de pregrado. Se describe el diseño de la investigación y presentan los resultados de cada uno de los estudios, para luego discutirlos en su conjunto.

\section{Método}

La investigación se compuso de tres estudios. El primero consistió en el análisis de los distintos programas de los cursos que se dictan en la carrera de psicología, con el propósito de levantar aquellas competencias declaradas en éstos. El interés principal fue apreciar la medida en que aparecían nuevas competencias propias de la psicología, no consideradas en el Proyecto Tuning. El objetivo de los estudios siguientes fue levantar aquellas competencias que los actores antes mencionados señalan como relevantes en la formación del psicólogo. En el segundo estudio, se recogió la opinión de estudiantes, exalumnos, profesores y profesionales a través de una encuesta consistente en ítem escalas de acuerdo e ítem de respuesta abierta, de manera de detectar aquellas competencias que dichos actores señalaran como de mayor relevancia. En el tercer estudio, 
se realizaron entrevistas cualitativas a profesores de la Facultad de Psicología con el doble objeto de levantar competencias relevantes para ellos, pero que no estaban expresadas en los programas de cursos considerados en el estudio n. ${ }^{\circ} 1$, y de complementar el levantamiento de competencias del estudio $n .{ }^{\circ} 2$, desde la perspectiva de la comunidad académica.

\section{Estudio n. ${ }^{\circ} 1$}

A partir de la planilla de horarios de cursos ofrecidos en la carrera de psicología, tanto para el segundo semestre de 2007 como para el primer semestre de 2008, se analizaron 69 programas de cursos que corresponden tanto a la formación básica (licenciatura) como a las líneas de especialización profesional (quinto año). En esta primera fase de análisis se procedió a la revisión, análisis y extracción de las diferentes competencias implicadas en los programas de cada curso por semestre.

Como se mencionó anteriormente, se tomó como punto de partida las distinciones del proyecto Tuning para reconocer, identificar y nombrar competencias presentes en los programas de curso. Dado que este marco no distingue competencias específicas de la formación de psicología, se consideraron como específicas aquéllas propias de cada uno de los programas revisados (es decir, las que se declaran en los programas como atributos que le dan un sentido formativo particular a cada curso) y que, ya sea por su especificidad o por su novedad, no aparecen determinadas en el proyecto Tuning.

Para el análisis de dichos programas dos psicólogos fueron entrenados para realizarlo. Éstos codificaron la totalidad de los programas en conjunto, desarrollando criterios comunes para la identificación de competencias. Una vez efectuado este ejercicio, y dado que aparecieron competencias relevantes que en el proyecto Tuning no estaban consideradas, se procedió a articularlas de una nueva manera. Para ello, el equipo trabajó con criterios sustantivos de articulación y contención de las competencias levantadas. 


\section{Resultados}

En la tabla n. ${ }^{\circ} 3$ se pueden apreciar las competencias propias del proyecto Tuning, y en la tabla $n .{ }^{\circ} 4$ aquellas que aparecieron producto del estudio que no estaban anticipadas en dicho proyecto y que fueron levantas durante el análisis.

Destaca como central en la disciplina, por su alta presencia en los programas, el área de conocimientos ligados a la misma, las habilidades de pensamiento y análisis que permiten articular ese conocimiento con la práctica (análisis crítico y competencia argumentativa, competencia interpretativa y de comprensión sistémica). Las siguen herramientas de intervención, como manejo de competencias de diseño, de autoconocimiento y manejo del rol profesional, discernimiento ético y responsabilidad social, entre otras.

Tabla n. ${ }^{\circ}$ 3. Competencias generales del proyecto Tuning.

\begin{tabular}{|l|l|l|}
\hline Competencias instrumentales & Competencias interpersonales & Competencias sistémicas \\
\hline - Capacidad de análisis y & - Capacidad crítica y & - Capacidad de aplicar los \\
síntesis & autocrítica & conocimientos en la práctica \\
- Capacidad de análisis crítico & - Trabajo en equipo & - Habilidades de investigación \\
- Capacidad de organizar y & - Habilidades interpersonales & - Capacidad de aprender \\
planificar & - Capacidad de trabajar en un & - Capacidad para adaptarse a \\
- Conocimientos básicos o & equipo interdisciplinar & los cambios \\
específicos del área & - Capacidad para comunicarse & - Creatividad (capacidad para \\
- Comunicación oral y escrita & con expertos de otras áreas & generar nuevas ideas) \\
- Conocimiento de una & - Apreciación de la diversidad & - Proactividad \\
segunda lengua & y multiculturalidad & - Conocimiento de culturas y \\
- Habilidades básicas de & - Compromiso ético & costumbres de otros países \\
manejo del ordenador & & - Habilidad para trabajar de \\
- Habilidad de gestión de la & & forma autónoma \\
información & & - Gestión de proyectos \\
- Resolución de problemas & & \\
- Toma de decisiones & & \\
\hline
\end{tabular}

Fuente: Beneitone, Pablo; Esquetini, César; González, Julia, et al. (eds.) (2007). 
Tabla n. ${ }^{\circ}$ 4. Competencias levantadas desde el análisis de programas de cursos.

\begin{tabular}{|c|c|}
\hline $\begin{array}{l}\text { - Competencia discursiva } \\
\text { - Competencia propositiva } \\
\text { - Competencia reflexiva o introspectiva } \\
\text { - Comprensión lectora } \\
\text { - Integración de conocimientos de otras } \\
\text { disciplinas } \\
\text { - Mirada crítica a los conocimientos aprendidos } \\
\text { - Comprensión de fenómenos } \\
\text { - Comprensión sistémica } \\
\text { - Producción de texto escrito } \\
\text { - Razonamiento matemático } \\
\text { - Toma de posición } \\
\text { - Análisis crítico } \\
\text { - Discernimiento ético } \\
\text { - Manejo de conocimientos instrumentales de } \\
\text { la psicología } \\
\text { - Aplicación de conocimientos teóricos a la } \\
\text { - Mráctica } \\
\text { - Manejo de conocimientos teóricos de } \\
\text { - Comicología y otras áreas } \\
\text { generación de hipótesis) } \\
\text { - Vinculación psicólogo-paciente } \\
\text { - Riseñono de propuestas de intervención } \\
\text { - Capacidad de conducir entrevistas } \\
\text { - Capacidad de escucha } \\
\text { - Capacidad de juego }\end{array}$ & $\begin{array}{l}\text { - Capacidad de elaborar propios procesos } \\
\text { - Competencia interpretativa } \\
\text { - Detección de necesidades } \\
\text { - Habilidades de manejo paciente-psicólogo } \\
\text { - Intervención psicoterapéutica en niños } \\
\text { - Responsabilidad social } \\
\text { - Autoconocimiento } \\
\text { - Generación de hipótesis } \\
\text { - Análisis de casos } \\
\text { - Trabajo en equipo interdisciplinario } \\
\text { - Apreciación por la diversidad y } \\
\text { - Calticulturalidad } \\
\text { - (flexibilididad) } \\
\text { - Creatividad (capacidad para generar nuevas } \\
\text { ideas) } \\
\text { - Liderazgo } \\
\text { - Conocimiento de culturas y costumbres de } \\
\text { - otros países } \\
\text { - Habilidad para trabajar en forma autónoma } \\
\text { - Gestión de proyectos } \\
\text { - Iniciativa y espíritu emprendedor } \\
\text { - Manejo de conocimientos básicos en uso de } \\
\text { - test } \\
\text { - Empatía } \\
\text { aplicación de conocimientos instrumentales } \\
\text { a la práctica }\end{array}$ \\
\hline
\end{tabular}

El listado anterior no parece a simple vista un conjunto de competencias específicas de la formación en psicología, al menos su mayoría. Sin embargo, si atendemos a éstas en su conjunto, particularmente aquellas que se repiten a través de los distintos cursos, es posible hipotetizar que el currículum se sostiene en una imagen del psicólogo como un profesional en el que las capacidades de análisis y comprensión son fundamentales. Si sumamos a esto que los conocimientos propios de la enseñanza abarcan tanto disciplinas fundantes como la filosofía y neurobiología, de las ciencias sociales como sociología y antropología, y de psicología básica, estas competencias de análisis, síntesis, comprensión, interpretación, argumentación, entre otras, son claves en el desarrollo de una perspectiva psicológica de lo humano, entendido en su naturaleza multidimensional y compleja. Esta hipótesis se confirma en el siguiente estudio. 
Por último, la articulación de competencias se hizo basada en cinco ejes. Esto implica que la distinción de Tuning de competencias sistémicas, instrumentales e interpersonales está reagrupada según cinco criterios generales: análisis y comprensión (pensamiento reflexivo e instrumental, ver tabla n. ${ }^{\circ}$ 5); comunicación (ver tabla n. ${ }^{\circ}$ 6); conocimientos (teóricos e instrumentales, ver tabla n. ${ }^{\circ} 7$ ); intervención (ver tabla n. ${ }^{\circ} 8$ ), e investigación (ver tabla n. ${ }^{\circ}$ 9). En este sentido, la articulación expresada en las tablas siguientes debe leerse de izquierda a derecha desde criterios generales de agrupación (los cinco ejes) que pueden servir para distintas disciplinas, hacia competencias progresivamente específicas.

Tabla n. ${ }^{\circ}$ 5. Agrupación según eje 1, pensamiento.

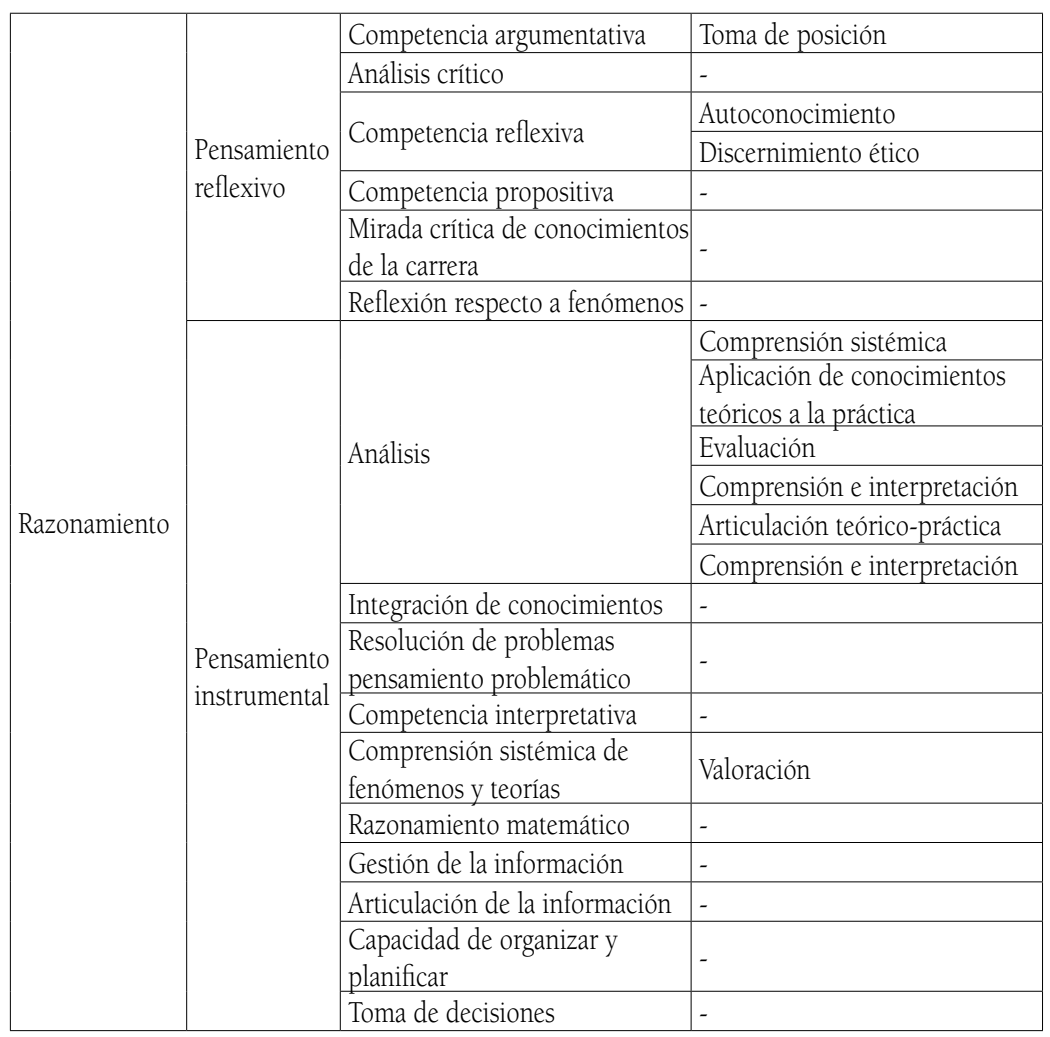


Tabla n. ${ }^{\circ}$ 6. Agrupación según eje 2, comunicación.

\begin{tabular}{|l|l|l|c|}
\hline \multirow{4}{*}{ Comunicación } & \multirow{2}{*}{ Comunicación oral } & Producción oral & - \\
\cline { 2 - 4 } & \multirow{3}{*}{ Comunicación escrita } & Competencia oral & - \\
\cline { 3 - 4 } & & Comprensión lectora & - \\
\cline { 3 - 4 } & & Producción de textos & - \\
\cline { 3 - 4 } & Manejo del computador & - \\
\hline
\end{tabular}

Tabla n. ${ }^{0}$ 7. Agrupación según eje 3, conocimientos.

\begin{tabular}{|l|l|l|l|}
\hline \multirow{4}{*}{ Conocimientos } & \multirow{3}{*}{$\begin{array}{l}\text { Conocimientos } \\
\text { teóricos }\end{array}$} & Conocimientos propios disciplina & - \\
\cline { 3 - 4 } & Conocimientos subdisciplinas psicológicas & - \\
\cline { 2 - 4 } & Conocimiento ciencias fundantes de la psicología & - \\
\cline { 2 - 4 } & $\begin{array}{l}\text { Conocimiento otras disciplinas ciencias sociales y biológicas } \\
\text { instrumentos }\end{array}$ & - \\
\cline { 3 - 4 } & Conocimientos básicos uso de test & - \\
\cline { 3 - 4 } & Conocimientos técnicas recolección información & - \\
\hline
\end{tabular}

Tabla n. ${ }^{\circ}$ 8. Agrupación según eje 4, intervención.

\begin{tabular}{|c|c|c|c|}
\hline \multirow{13}{*}{ Intervención } & \begin{tabular}{|l|} 
Diseño de \\
intervención
\end{tabular} & $\begin{array}{l}\text { Aplicación conocimientos } \\
\text { instrumentales a la práctica }\end{array}$ & - \\
\hline & \multirow{4}{*}{$\begin{array}{l}\text { Estrategias de } \\
\text { intervención }\end{array}$} & $\begin{array}{l}\text { Aplicación conocimientos teóricos } \\
\text { a la práctica }\end{array}$ & - \\
\hline & & Trabajo en equipo interdisciplinario & - \\
\hline & & Responsabilidad social & - \\
\hline & & Habilidad para trabajar en equipo & - \\
\hline & \multirow{3}{*}{$\begin{array}{l}\text { Detección de } \\
\text { necesidades }\end{array}$} & Capacidad crítica y autocrítica & Habilidades de investigación \\
\hline & & Capacidad de escucha & 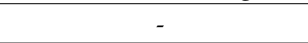 \\
\hline & & Habilidades de investigación & 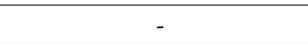 \\
\hline & \multirow{2}{*}{\begin{tabular}{|l} 
Evaluación \\
intervención
\end{tabular}} & Medición & $\begin{array}{l}\text { Aplicación conocimientos } \\
\text { instrumentales a la práctica }\end{array}$ \\
\hline & & Habilidades de aplicación de test & - \\
\hline & \multirow{3}{*}{$\begin{array}{l}\text { Reflexión sobre } \\
\text { rol profesional }\end{array}$} & Elaboración propios procesos & - \\
\hline & & Capacidad de negociación & - \\
\hline & & Discernimiento ético & - \\
\hline
\end{tabular}


Tabla n. ํ 9. Agrupación según eje 5, investigación.

\begin{tabular}{|c|c|c|c|}
\hline \multirow{8}{*}{ Investigación } & \multirow{3}{*}{ Aplicación de conocimientos teóricos } & Conocimiento riguroso & - \\
\hline & & Pensamiento problemático & - \\
\hline & & Generación de hipótesis & - \\
\hline & \multirow{2}{*}{$\begin{array}{l}\text { Aplicación conocimientos } \\
\text { instrumentales }\end{array}$} & Manejo de técnicas de investigación & - \\
\hline & & Razonamiento matemático & - \\
\hline & \multirow{3}{*}{$\begin{array}{l}\text { Diseño de investigaciones, proyectos } \\
\text { de investigación }\end{array}$} & Capacidad propositiva & - \\
\hline & & Competencia argumentativa & - \\
\hline & & Producción de textos & - \\
\hline
\end{tabular}

\section{Estudio n. ${ }^{\circ} 2$}

Este estudio tuvo como objetivo identificar qué competencias de aquellas que se levantaron en el estudio n. ${ }^{\circ} 1$ eran más o menos relevantes para los actores de la comunidad académica de la Facultad de Psicología de la Universidad Alberto Hurtado, y para psicólogos que se desempeñan en distintas áreas del quehacer profesional. Para ello se desarrolló una encuesta de carácter autoadministrable, la cual se dispuso en papel para los estudiantes de la carrera, y en formato electrónico para exalumnos, profesores y profesionales.

Respondieron la encuesta 143 estudiantes, 64 profesionales y 11 profesores $^{5}$. De los 143 estudiantes que respondieron, 22 casos fueron excluidos del análisis por responder un porcentaje muy bajo de los ítems del instrumento. Respecto a los profesores participantes, se presentan los resultados aunque éstos representan aproximadamente sólo un $15 \%$ del total de profesores a quienes se hizo llegar el instrumento.

Con respecto a los estudiantes, el 68\% de los participantes correspondió a los tres primeros años de la carrera. El restante 32\% se distribuyó de manera relativamente homogénea entre los dos restantes años de formación (ver tabla n. ${ }^{\circ} 10$ ).

5 En un principio se incluyó entre los destinatarios de la encuesta a exalumnos de la carrera. Sin embargo, el número de respuestas obtenidas fue tan bajo, que se optó por excluirlos del análisis y presentación de resultados del estudio. 
Tabla n. ${ }^{\circ}$ 10. Distribución del grupo de estudiantes participantes, por edad y año de carrera.

\begin{tabular}{|c|c|c|c|c|c|c|c|c|c|c|c|}
\hline Edad & \multicolumn{2}{|c|}{ ler año } & \multicolumn{2}{|c|}{ 2do año } & \multicolumn{2}{c|}{ 3er año } & \multicolumn{2}{|c|}{4 to año } & \multicolumn{2}{|c|}{ 5to año } & Total (\%) \\
\hline & $\mathrm{n}$ & $\%$ & $\mathrm{n}$ & $\%$ & $\mathrm{n}$ & $\%$ & $\mathrm{n}$ & $\%$ & $\mathrm{n}$ & $\%$ & \\
\hline $18-19$ & 23 & 16 & 9 & 6 & 2 & 1 & 0 & 0 & 0 & 0 & 24 \\
\hline $20-21$ & 9 & 6 & 29 & 20 & 5 & 3 & 2 & 1 & 0 & 0 & 32 \\
\hline $22-23$ & 1 & 1 & 3 & 2 & 7 & 5 & 10 & 7 & 11 & 8 & 22 \\
\hline $24-60$ & 2 & 1 & 3 & 2 & 5 & 3 & 9 & 6 & 13 & 9 & 22 \\
\hline Total & 35 & 24 & 44 & 31 & 19 & 13 & 21 & 15 & 24 & 17 & 100 \\
\hline
\end{tabular}

Con respecto a los profesionales, la encuesta fue respondida por 64 egresados de psicología de diferentes universidades (59\% mujeres y $41 \%$ hombres). La edad de éstos fluctuó entre 22 y 59 años, reportándose entre 1 y 34 años de ejercicio profesional. Con respecto al área de egreso, un 25,8\% reportó especialidad clínica; $21,2 \%$, educacional; $16,7 \%$, laboral; $10 \%$ otras especialidades; $21,2 \%$, ninguna, y $4,5 \%$ no la reportó. Por otra parte, un $27,3 \%$ de los profesionales al momento de la encuesta se desempeñaba en el área educacional, 28,8\% en clínica, 19,7\% en laboral, 9,1\% en comunitaria, y $15 \%$ en otras áreas.

Los docentes que respondieron la encuesta fueron 11, 4 de ellos mujeres. Su edad abarcó entre los 30 y los 49 años. Se reportaron 6 como psicólogos clínicos, 3 como educacionales, 1 como laboral y 1 como social-comunitario.

Con respecto a la encuesta utilizada, en ésta se solicitó a los participantes que indicaran el grado en que debiese desarrollarse una serie de competencias (aquéllas sistematizadas en el estudio $\mathrm{n}^{\circ}$ 1), a través de una escala de estimación (tipo Likert) presentada a continuación de cada competencia-ítem (en total, 54). Además, se dio la opción de que el encuestado agregara alguna competencia si percibía que no estaba siendo considerada.

La encuesta tuvo cuatro formatos, uno por actor. Se aplicó el coeficiente Alpha de Cronbach para medir la confiabilidad del instrumento por cada grupo de actor involucrado en la investigación. El grado de confianza para profesionales $(r=0,87)$, como profesores $(r=0,90)$ y estudiantes $(r=0,91)$, nos indica un resultado muy aceptable, aun considerando el efecto del alto número de ítems de 
la encuesta y del número de encuestados por tipo de actor, sobre la estimación del coeficiente de consistencia interna.

\section{Resultados}

Los resultados del estudio pueden parecer sorprendentes, en el siguiente sentido: se podría decir que para todos los encuestados, prácticamente todas las competencias son importantes. Esto es llamativo, pues por un lado nos habla de una representación difusa de las competencias más relevantes para un psicólogo. Por otro, indica que se exige al psicólogo el dominio de una serie de competencias que podría catalogarse como abrumante. Sin embargo, debemos tener en cuenta la probabilidad de que el instrumento no haya sido lo suficientemente sensible como para detectar diferencias existentes entre los participantes del estudio. Adicionalmente, la cantidad de participantes de la muestra fue muy baja en un grupo (profesores) y muy diferente en número entre los grupos. En la tabla n. ${ }^{\circ} 11$ se presentan los resultados de competencias consideradas muy importantes por más del 95\% de los encuestados por tipo de actor. Se escogió este punto de corte para identificar las respuestas más altamente compartidas entre los diferentes actores. 
Tabla n. ${ }^{\circ} 11$. Competencias más frecuentemente consideradas como muy importantes, según tipo de actor.

\begin{tabular}{|c|c|c|}
\hline Estudiantes & Profesores & Profesionales \\
\hline $\begin{array}{l}\text { Capacidad de argumentación }(*) \\
\text { Capacidad de escucha }(+) \\
\text { Capacidad de interpretación }(*) \\
\text { Capacidad de realizar } \\
\text { propuestas } \\
\text { Capacidad para aplicar los } \\
\text { conocimientos en la práctica } \\
(* *) \\
\text { Comprensión de fenómenos } \\
\text { psicosociales }\left(^{*}\right) \\
\text { Comprensión lectora }(*) \\
\text { Compromiso ético }(* *) \\
\text { Manejo de herramientas de } \\
\text { intervención } \\
\text { Preocupación por la calidad }\end{array}$ & $\begin{array}{l}\text { Capacidad de adaptarse a } \\
\text { nuevas situaciones } \\
\text { Capacidad de análisis crítico } \\
(* * *) \\
\text { Capacidad de análisis y síntesis } \\
(* * *) \\
\text { Capacidad de argumentación }\left(^{*}\right) \\
\text { Capacidad de comprender } \\
\text { sistémicamente } \\
\text { Capacidad de escucha }(+) \\
\text { Capacidad de interpretación }\left(^{*}\right) \\
\text { Capacidad de persuadir } \\
\text { Capacidad interpersonal de } \\
\text { crítica y autocrítica } \\
\text { Capacidad para comunicarse } \\
\text { con expertos de otras áreas } \\
\text { Comprensión de fenómenos } \\
\text { psicosociales }(*) \\
\text { Comprensión lectora }(*) \\
\text { Comunicación oral y escrita } \\
\text { Conocimientos básicos o } \\
\text { específicos del área (psicología) } \\
\text { Desarrollo de la relación } \\
\text { psicólogo-paciente/cliente } \\
\text { Detección de necesidades en } \\
\text { una institución/organización } \\
\text { Habilidad para trabajar en } \\
\text { forma autónoma } \\
\text { Preocupación por la calidad } \\
\text { Reflexión sobre fenómenos } \\
\text { humanos } \\
\text { Trabajo en equipo }\end{array}$ & $\begin{array}{l}\text { Capacidad de análisis crítico } \\
(* * *) \\
\text { Capacidad de análisis y síntesis } \\
(* * *) \\
\text { Capacidad de escucha }(+) \\
\text { Capacidad para aplicar los } \\
\text { conocimientos en la práctica } \\
(* *) \\
\text { Compromiso ético }(* *)\end{array}$ \\
\hline
\end{tabular}

Observación: se presentan las respuestas que tuvieron una frecuencia de respuesta "muy importante" superior a $95 \%$.

$\left({ }^{*}\right)$ Respuestas compartidas entre estudiantes y profesores

$\left.{ }^{* *}\right)$ Respuestas compartidas entre estudiantes y profesionales

$(* * *)$ Respuestas compartidas entre profesores y profesionales

(+) Respuestas compartidas entre los tres actores

En la tabla n. ${ }^{\circ} 12$ se pueden observar las competencias que fueron respondidas como "muy importantes" por menos del 70\% de los encuestados. Se escogió este punto de corte, análogamente al punto de corte antes reportado, debido al gran número de respuestas 
"muy importantes" obtenidas y a la necesidad de establecer un límite para interpretar los datos.

Tabla ${ }^{0} 12$. Competencias menos frecuentemente consideradas como muy importantes según tipo de actor.

\begin{tabular}{|c|c|c|}
\hline Estudiantes & Profesores & Profesionales \\
\hline $\begin{array}{l}\text { Capacidad de persuadir }(* *) \\
\text { Conocimiento de culturas y } \\
\text { costumbres de otros países }(+) \\
\text { Conocimiento de una segunda } \\
\text { lengua }(* *) \\
\text { Habilidades básicas de manejo } \\
\text { de computador }(+) \\
\text { Producción de textos }(* *) \\
\text { Razonamiento matemático }(* *)\end{array}$ & $\begin{array}{l}\text { Capacidad de juego }(* * *) \\
\text { Conocimiento de culturas y } \\
\text { costumbres de otros países }(+) \\
\text { Conocimientos básicos del uso } \\
\text { de test }(* * *) \\
\text { Creatividad: capacidad para } \\
\text { generar nuevas ideas } \\
\text { Gestión de proyectos } \\
\text { Habilidad para trabajar en un } \\
\text { contexto internacional }(* * *) \\
\text { Habilidades básicas de manejo } \\
\text { de computador }(+) \\
\text { Iniciativa y espíritu } \\
\text { emprendedor }(* * *) \\
\text { Manejo de conocimientos } \\
\text { de ciencias fundantes de la } \\
\text { psicología (***) } \\
\text { Toma de decisiones }\end{array}$ & $\begin{array}{l}\text { Capacidad de juego }(* * *) \\
\text { Capacidad de persuadir }(* *) \\
\text { Conocimiento de culturas y } \\
\text { costumbres de otros países }(+) \\
\text { Conocimiento de una segunda } \\
\text { lengua }(* *) \\
\text { Conocimientos básicos del uso } \\
\text { de test }(* * *) \\
\text { Habilidad para trabajar en un } \\
\text { contexto internacional }(* * *) \\
\text { Habilidades básicas de manejo } \\
\text { de computador }(+) \\
\text { Habilidades de investigación } \\
\text { Iniciativa y espíritu } \\
\text { emprendedor }(* * *) \\
\text { Liderazgo } \\
\text { Manejo de conocimientos } \\
\text { de ciencias fundantes de la } \\
\text { psicología }(* * *) \\
\text { Producción de textos }(* *) \\
\text { Razonamiento matemático }(* *)\end{array}$ \\
\hline
\end{tabular}

Observación: se presentan las respuestas que tuvieron una frecuencia de respuesta "muy importante" inferior a $70 \%$.

$(* *)$ Competencias compartidas entre estudiantes y profesionales

$(* * *)$ Competencias compartidas entre profesores y profesionales

(+) Competencias compartidas entre los tres actores

Para variar la perspectiva de lectura de los datos, se pusieron en relación los resultados de los actores, comparando entre sí el porcentaje de respuestas "muy importante" de cada competencia, luego estableciendo la mediana entre las tres cifras y organizando las respuestas según la magnitud de la mediana. Eso arrojó un ranking de respuestas organizado según porcentaje y mediana de respuestas. De este ranking se presentan las ocho competencias más frecuentes (ver tabla n. ${ }^{\circ}$ 13) y las ocho menos frecuentes (ver tabla n. ${ }^{\circ} 14$ ), considerando estudiantes, docentes y profesionales. 
Tabla n. ${ }^{\circ}$ 13. Competencias más frecuentemente consideradas muy importantes.

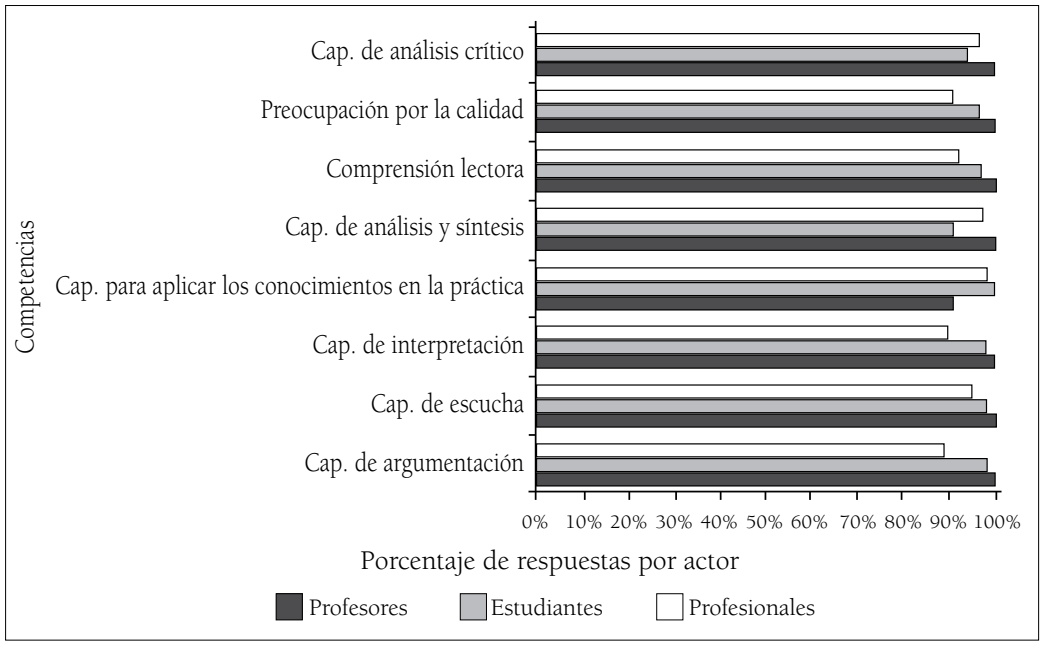

Como se puede observar en la tabla n. ${ }^{\circ} 13$, las competencias consideradas difieren de las reportadas previamente (tabla n. ${ }^{\circ}$ 11), debido a que esta vez no se consideró un punto de corte, privilegiándose el hallazgo de respuestas comunes entre los tres actores. Ello mueve la frecuencia de respuestas por debajo del 90\% en algunos casos.

En cambio en la tabla n. ${ }^{\circ} 14$, se presentan las ocho competencias con una mediana de menor magnitud. En esta tabla se reflejan respuestas que no necesariamente son bajas; más bien, muestran diferencias de valoración entre los actores. Así, la "habilidad para trabajar en un contexto internacional" y el "conocimiento de culturas y costumbres de otros países" aparecen como competencias notoriamente más valoradas por los estudiantes, mientras que la "capacidad de persuadir" y el "razonamiento matemático" son mucho más valoradas por los profesores de la facultad que por los estudiantes y los profesionales encuestados. Otro resultado destacable es que la "capacidad de juego" es notablemente menos valorada entre los docentes que entre los estudiantes y los profesionales. 
Tabla n. ${ }^{\circ}$ 14. Competencias menos frecuentemente consideradas muy importantes.

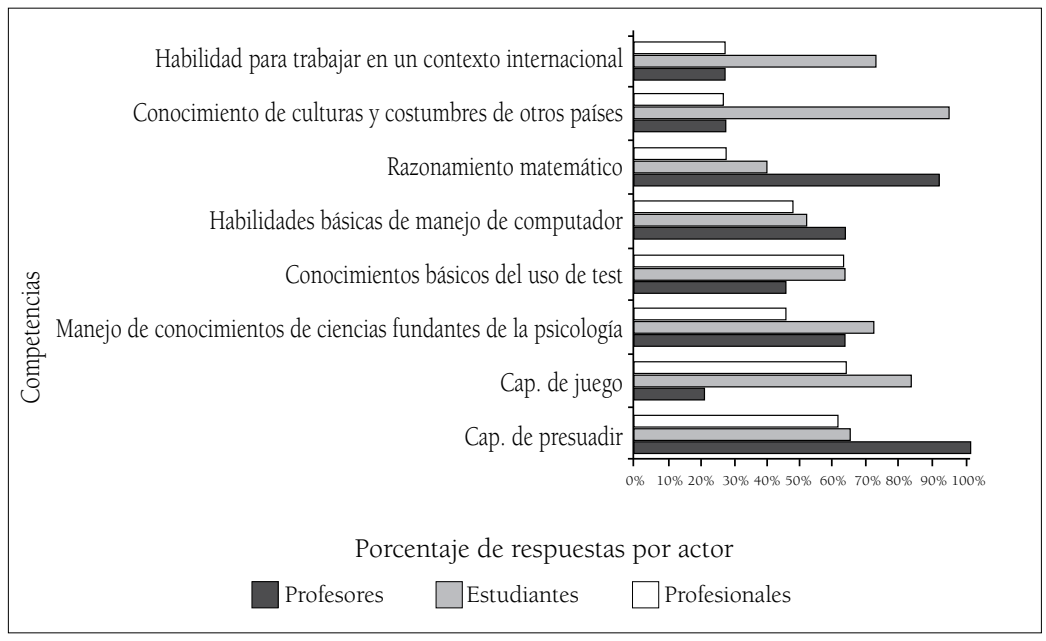

Si se atiende a las coincidencias de los diferentes actores en aquello que consideran más o menos importante en la formación de todo psicólogo, destacan cuatro puntos: (1) todos los actores coinciden en considerar como muy relevante la "capacidad de escucha"; (2) en destacar la importancia del manejo de conocimientos de la disciplina por parte del profesional de la psicología; (3) existe un alto acuerdo entre los actores en considerar en un alto porcentaje competencias de análisis y comprensión como muy relevantes, las que ocupan incluso una proporción importante de las competencias que cada actor considera como más relevantes; (4) habilidades técnicas como uso de test no son consideradas como muy importantes con tan alta coincidencia, e incluso profesores y profesionales las consideran de las menos relevantes.

Lo anterior es interesante no sólo porque muestren elementos comunes entre los actores. Tampoco porque en sí mismas cada una de estas competencias sea específica de la psicología, sino porque en su conjunto sugieren una imagen particular del psicólogo que es compartida entre los actores. Al articular estas competencias entre sí lo que se levanta es una noción de un profesional que no está orientado primeramente a la acción efectiva, sino que requiere "escuchar". Una escucha que trasciende la connotación clínica y probablemente puede 
entenderse como una actitud de receptividad, de ser a quien se le relata una experiencia o palabra que es necesario (y que le demanda) comprender, analizar, interpretar. Esta comprensión, sin embargo, no se desarrolla en el sentido común, sino a partir de conceptos y relaciones conceptuales provenientes tanto de la psicología misma como disciplina (teorías propiamente psicológicas), como de otros ámbitos de las ciencias sociales y biología. En este contexto, la competencia no tiene que ver con alguien que sólo comprende conceptos, sino que es capaz de comprender cierta experiencia humana (ajena) con una mirada disciplinar que le permiten entenderla como producto de aspectos socio-histórico-culturales, biológicos y psíquicos, y a diferentes niveles. En consecuencia, el núcleo común de todo psicólogo no estaría primeramente dado por una respuesta, resolución de problemas, o aplicación de ciertas técnicas.

Ahora bien, más allá de los elementos comunes, los distintos actores presentan diferencias notorias en aquellas competencias que su mayoría reconoce como muy importantes. Por ejemplo, mientras profesores y estudiantes coinciden en considerar muy frecuentemente como relevante para el psicólogo la capacidad de argumentación, estudiantes y profesionales consideran poco frecuentemente la "capacidad de persuadir" como muy importante (al contrario de los profesores). Mientras los profesores relevan el carácter retórico de la disciplina, en tanto no sólo se trata de argumentar y fundamentar las afirmaciones profesionales, sino de levantar cierto punto de vista que debe ser aceptado por clientes o pares, los estudiantes enfatizan la necesidad de fundamentar sus opiniones, pero no la necesidad de posicionar un punto de vista.

Cabe preguntarse si estas divergencias obedecen a las distintas concepciones que los actores tienen acerca de lo que es una competencia en general, y a aquéllas consideradas como nucleares y propias de un psicólogo en particular. Al respecto, no conviene olvidar que las valoraciones de las personas tienen relación con sus procesos de socialización y con las redes sociales en que están inmersos (Asún, 2006). En este sentido, se puede pensar que los actores encuestados tienen distintas perspectivas de las competencias psicológicas, según el tipo de participación en la disciplina y su 
vinculación a la formación y desempeño de la profesión. Por ejemplo, respecto a los profesores de la carrera, se debe tener en cuenta que ellos corresponden a un tipo de estudiante exitoso en el pasado, que en la actualidad puede dedicar tiempo a la actividad profesional no académica, pero que en lo fundamental es convocado desde una perspectiva articulada en torno a su carácter de académico formador. En este sentido, puede entenderse que ellos destaquen las competencias analítico-sintéticas, comprensivas e interpretativas, junto con un grupo importante de competencias relacionadas con la comunicación profesional y académica. Por su parte, los denominados "profesionales" corresponden a un grupo que, identificándose con la disciplina psicológica y asumiendo que pueden tener funciones académicas y que tuvieron roles estudiantiles, responden el estudio desde su inmersión en un campo de desempeño profesional. En este sentido, es interesante que las respuestas del grupo estén cohesionadas en torno a las capacidades analítico-sintéticas por una parte, y las competencias de aplicación, por otro. Es, en cierto sentido, reflejo de un tipo de actividad en que es exigible la destreza de articular el pensamiento con las necesidades de incidir en un determinado orden de cosas desde la especificidad disciplinar. Refuerza esta interpretación la aparición del compromiso ético como competencia valorada, pues desde una perspectiva profesional aparecen los aspectos políticos y éticos de la práctica de la psicología.

Los estudiantes sostienen una perspectiva coherente con el hecho de ser psicólogos en preparación. A diferencia de los dos actores anteriores, su punto de vista no incluye la experiencia de académicos y profesionales, sino que es una proyección en que se cruzan la experiencia espontánea que pudiera tener cualquier individuo en el quehacer de la psicología (sentido común psicológico) con lo que la formación misma contribuye a desarrollar como representación de la psicología. En este sentido, se podría esperar un punto de vista similar con el de los profesores. Sin embargo, esto sólo es parcial. Las dimensiones que pueden identificarse a partir de las respuestas de los estudiantes corresponden, por un lado, a competencias comprensivas e interpretativas, y por otro, a una dimensión activa y ética volcada a la intervención. En consecuencia, los estudiantes ocupan una posición intermedia entre académicos y profesionales, compartiendo con los 
primeros las competencias comprensivas e interpretativas, y con los segundos un énfasis práctico del quehacer disciplinar.

\section{Estudio n. ${ }^{\circ} 3$}

Como una manera de complementar y explorar los resultados del estudio anterior, el estudio n. ${ }^{\circ} 3$ tuvo por finalidad profundizar entre los académicos ligados a la carrera de psicología aquellas competencias consideradas relevantes y que caracterizan a un psicólogo en general en sus respectivas áreas de especialización.

Se realizaron entrevistas a 11 docentes de la Facultad. El proceso de muestreo arrancó considerando las siguientes variables: área de especialización profesional, sexo y tipo de contrato. Adicionalmente, a lo largo del análisis se consideró relevante entrevistar a profesores que se desempeñaran en los cursos de plan básico y licenciatura de la carrera, independientemente de su área de especialización. La muestra de profesores participantes quedó constituida por cuatro mujeres y siete hombres; cinco profesores con contrato de planta y dos de plan básico y licenciatura.

Las entrevistas tuvieron carácter estructurado, con un guion especialmente diseñado, y fueron realizadas por dos entrevistadoras. La mayor parte de las entrevistas se realizó en la UAH. Éstas fueron grabadas y transcritas, y luego analizadas por la Unidad de Investigación Cualitativa (UIC) de la Facultad de Psicología.

A partir de este estudio, se identificaron en el discurso de los profesores dos tipos de competencias descritas como necesarias para el desempeño del psicólogo: aquéllas transversales a la carrera y que deben presentar todos los psicólogos sin importar su área de especialización, y aquéllas propias de cada especialidad.

Con respecto a las competencias transversales, tres son señaladas por todos los profesores como fundamentales para la formación del psicólogo. Estas competencias son (en orden de importancia): (1) dominio metodológico y sistematicidad, (2) habilidades de análisis, y (3) manejo conceptual mínimo. Luego, la mayoría de los profesores 
adhiere a la importancia de desarrollar la competencia de reflexividad, ya sea como una forma de pensamiento general o como la capacidad de reflexionar sobre el rol profesional. También se enfatiza el compromiso ético (mencionado por la mitad de los profesores aproximadamente), flexibilidad (nombrada en especial por psicólogos educacionales y laborales), y competencias relativas a la persona, tales como empatía, humildad y apertura.

Esto por una parte viene a indicar que, aunque pocos profesores contestaron la encuesta, ésta recogió una perspectiva compartida. Adicionalmente, los resultados de este estudio ayudan a enriquecer la imagen del psicólogo que apareció en el Estudio n. ${ }^{\circ} 2$ y que era ampliamente compartida entre los actores. Además de un profesional que "escucha", analiza, interpreta y comprende a la luz de maneras de concebir propias de la especialidad, se agrega un aspecto de reflexión sobre la propia práctica ya sea con respecto al tipo de análisis o al rol profesional. En esta medida, es un profesional que está orientado en dar una respuesta a otro (pero no dirigido primariamente a la acción), y que como tal necesita ciertas habilidades para relacionarse con ese otro; pero además es un profesional que en vista de responder con propiedad debe dirigirse sistemáticamente hacia sí mismo para evaluar y ofrecer una respuesta adecuada.

Ahora bien, más allá de lo anterior los entrevistados parecen fallar en dar cuenta de competencias del psicólogo de otras especialidades. Ante la pregunta por competencias en las áreas de especialidad nos encontramos con respuestas como: “(...) No tengo idea (...)" (entrevistado 6), "(...) Realmente no sé mucho lo que hace el psicólogo educacional (...)” (entrevistado 3), o “(...) El psicólogo comunitario en aquella época era como un psicólogo que estaba metido en la población, en la comunidad, no sé si sigue haciendo lo mismo en realidad (...)" (entrevistado 2).

Aparentemente, y a pesar de compartir una formación común, el trabajo especializado en un área limita progresivamente la posibilidad de conversación entre especialidades, haciendo perder de vista aquello que es común y transversal a todas las especialidades, y aquello que es único de cada una de ellas. Los entrevistados expresan la necesidad 
de establecer puentes entre áreas que les permitan evidenciar las competencias genéricas que se potencian y que tienen su especificidad de acuerdo con el contenido particular de cada área:

"(...) Yo creo que en el área educacional compartimos un ámbito de conocimientos, entre los organizacionales y los educacionales, que [...] no siempre vemos y creo que podríamos establecer más puentes, en ciertos ámbitos ya sea... de comprensión y cambio institucional [...] cuando los educacionales lo abordan, yo creo que hay herramientas de nuestra área, y a la vez nosotros cuando hablamos de procesos de aprendizaje y de diseño [...] de cambio... o... de formación, que también es relevante verlo desde el lado educacional" (entrevistado 8).

Por último, es importante notar que aquellos profesionales que tuvieron notoria dificultad para enunciar competencias de las diferentes especialidades evidenciaron mayor facilidad para explicitar los saberes (conocimientos) para considerar en cada una de las áreas. Por ejemplo: "el psicólogo educacional tiene que tener una muy buena formación en psicología evolutiva... una muy buena educación en el ámbito de lo que es el aprendizaje (...)" (entrevistado 5); "[el psicólogo clínico] muchos conocimientos, manejo de una técnica bien rigurosa (...)" (entrevistado 4); "[el psicólogo laboral] creo que tiene que manejar todos los temas relacionados a una empresa, a una organización (...)" (entrevistado 11). Esto puede guardar relación con el hecho de que los profesores al ser interpelados como tales pierden de vista el área de desempeño profesional de las especialidades, particularmente aquellas con las que no se relacionan en su vida académica, pudiendo sólo esbozar el área de conocimiento que caracteriza determinada subdisciplina pero no las competencias con las que "cobran vida" esos conocimientos en el quehacer profesional.

Dicho lo anterior, más allá de las dificultades en dar cuenta de las competencias, las respuestas de los docentes se pueden agrupar según dos perspectivas. La primera es una mirada profesional, es decir, se identifican aquellas competencias necesarias para desempeñarse eficientemente en el ejercicio profesional, por ejemplo: 
"Haber adquirido el conocimiento básico necesario durante pregrado [...], haber cursado todas las etapas que debe cursar un profesional digamos para llegar a un nivel de competencia mínimo para salir al ejercicio laboral (...)" (entrevistado 5).

En otro caso:

"Rigurosidad profesional, en términos de... que lo asocio mucho en esta capacidad de, en la capacidad analítica, o sea... creo que, creo que el... parte importante del [...] rol de un psicólogo es poder mirar rigurosamente [...] las problemáticas, [...] y poder dar soluciones que, que sean responsables, que sean, [...] atingentes (...)" (entrevistado 11).

La segunda perspectiva identifica las competencias distintivas del psicólogo en relación con otras profesiones. La capacidad de observar fenómenos, de análisis y síntesis, de generar hipótesis, la curiosidad y la precisión conceptual se configuran como competencias distintivas:

"(...) Siempre trabajas con problemas y tienes que dilucidar cuál es el problema que tienes que investigar, entonces eso implica tener una cierta claridad, o llegar a una claridad después de un ejercicio eeeh, que implica cotejar mucha información y luego determinar qué es lo fundamental y cuáles son las posiciones contradictorias de esas informaciones, y cuál, qué es lo relevante entonces de investigar" (entrevistado 10).

"(...) Debe tener una buena capacidad para generar hipótesis... es decir, debe ser capaz de [...] seleccionar información, de tomar decisión respecto de qué información es relevante para la construcción de una hipótesis respecto de algún problema planteado... eso en términos generales [...] lo cual arrastra otras capacidades que son de base, como tener una capacidad de abstracción sobre la media, tener capacidad de síntesis (...)" (entrevistado 2). 


\section{Discusión}

En su conjunto los resultados de los tres estudios levantan cuestiones de interés para la formación de psicología, tanto desde una perspectiva de gestión curricular como de las competencias que debieran garantizarse en la formación de pregrado, lo que no es privativo de la Facultad de Psicología en donde se realiza el estudio. Por otro lado, el estudio sugiere cuestiones relevantes para la reflexión en torno a las competencias.

Lo primero que surge con mucha fuerza desde los tres estudios es que competencias de análisis, comprensión e interpretación, caracterizan de manera distintiva la mirada del psicólogo, dado cierto ámbito de conocimiento. Podría pensarse que este énfasis es coherente con la misión de la facultad y la universidad que acogen la investigación, y claramente es el caso. Sin embargo, el énfasis de los profesionales, aunque interpelados por la institución, probablemente apunta a una cuestión propia de la disciplina psicológica. En este sentido, y haciendo abstracción por un minuto de los conocimientos específicos que iluminan ese comprender y analizar, estas competencias, que pueden ser compartidas por muchas profesiones, particularmente de las ciencias humanas y sociales, en los psicólogos aparecen como distintivas. No estamos hablando de herramientas generales de sistematización y ordenamiento de información, sino competencias que caracterizan un quehacer que consiste en una reinterpretación de una palabra dada como preparación de una respuesta o propuesta. En consecuencia es un quehacer eminentemente generativo y propositivo, pero cuya materia prima es la experiencia de un individuo, grupo o colectividad. Claramente este proceso de recreación requiere tener herramientas teóricas para comprender esas experiencias que, en tanto experiencias de uno o más sujetos, son fruto de procesos complejos a diferentes niveles y de diferente naturaleza.

Este núcleo de competencias de análisis y reflexión por sobre competencias técnicas, más el hecho de que los profesores en las entrevistas hayan tenido grandes dificultades para dar cuenta de competencias propias de las distintas especialidades, refuerza la idea de que el psicólogo generalista no está definido por su capacidad 
técnica, sino por la dinámica de pensamiento que está detrás de la comprensión de la experiencia del sujeto. Esto tiene implicancias importantes para la reflexión en torno al currículum de psicología: la tendencia a priorizar la enseñanza de cuestiones técnicas a momentos tempranos de la formación no puede ocurrir a costa de los espacios en el currículum en los que a propósito de teorías, propuestas conceptuales, u otros conocimientos, se enseña a pensar y comprender la experiencia humana.

Adicionalmente, el hecho de que los diferentes actores tengan marcadas divergencias ligadas al tipo de participación que tienen en la disciplina da cuenta que las competencias que caracterizan a un profesional y que deben orientar la formación en psicología, no están dadas meramente por una cuestión de mercado independiente de la experiencia de quienes hacen la psicología, sino que es una cuestión muy compleja determinada en parte por el sistema productivo y mercado laboral, pero en parte muy importante por una interacción dinámica de respuestas de diferentes actores en psicología a las demandas mediatas e inmediatas de su quehacer. Es necesario prestar atención, entonces, a los procesos de desarrollo y cambio curricular poniendo sobre la mesa su dimensión política, normalmente escondida tras el velo de la cientificidad y la tecnología educativa.

Considerando nuevamente las dificultades de los profesores en dar cuenta de las competencias del psicólogo, es necesario abordar una cuestión central del estudio que fue esbozado en los antecedentes: la noción de competencias. El estudio intencionadamente no explicitó lo que se entendía por competencias al preguntar por ellas, asumiendo la vaguedad del término desde el sentido común. De esta manera, los actores respondieron desde un campo dinámico y heterogéneo de sentidos que probablemente dificultó y tensionó, sobre todo para los docentes, el marco de respuestas. Asimismo, el estudio plantea una cuestión que abre un camino para concebir lo que es una competencia. El hecho de que se levantaran con énfasis importante prácticas de análisis y comprensión como algo distintivo del psicólogo y quedara algo menos claro la relevancia para todos los actores de las prácticas técnicas, sugiere que para comprender las competencias en esta disciplina es absolutamente necesario ser capaz de concebir una 
competencia, por un lado, con un énfasis importante en prácticas de pensamiento, y por otro, no necesariamente en juego en función de su utilidad técnica. Siguiendo esta línea es relevante traer a colación la noción de competencia trabajada por la $\operatorname{OECD}(2000 ; 2004)$ en los marcos conceptuales de ciertas evaluaciones internacionales como IALS y PISA, como contrapartida del concepto de alfabetización. Desde esta perspectiva, ser competente y ser alfabeto en una determinada área, son dos caras de una misma moneda. Esto sugiere que ser competente involucra ser capaz de manejar ciertos sistemas semióticos (lenguaje escrito, matemáticas, digital) para concebir los eventos cotidianos a través de cierto sistema conceptual.

Más que la movilización de recursos internos de diversa índole, esta noción está íntimamente ligada a procesos discursivos. De alguna u otra manera, lo que se aventura es que ser competente es ser un hablante eficiente de cierto lenguaje, un participante activo dentro de una comunidad disciplinar. A partir de esto se podría concebir una competencia ligada a la noción de género discursivo propuesta por Bajtín (2002). Primero, pues concebimos que toda situación a la que se responde es una situación social. Luego, porque toda situación social no es única e irrepetible, sino que corresponde a una clase (algo reconocido por Perrenoud, 2004) de situaciones, o tipos de situaciones sociales. Tercero, porque responder en una situación social implica un acto discursivo, esto es, un decir. Y para que este decir sea respondido (podríamos decir efectivo) es necesario ser hablante de ese género, ser parte de cierta cadena de interacciones discursivas, participar de una historia de discusiones, de conceptos y conocimientos, y ser capaz de proponer dentro de esta cadena histórica nuevos puntos de vista, nuevas soluciones, perspectivas, entre otros. Ser competente profesionalmente hablando sería ser capaz de manejar un conjunto heterogéneo de géneros discursivos (clases) propios de una disciplina, de ser hablantes de esta disciplina no en el sentido de dar cuenta del conocimiento, sino de responder a la diversidad de situaciones concretas que en el ejercicio profesional aparecen.

A diferencia de la noción de competencias antes discutida y ampliamente aceptada, aquí no se trata de primero tener recursos y después combinarlos. Aprender es siempre responder, y en toda 
respuesta no hay una unión de elementos, sino que se despliega una totalidad que sólo posteriormente, y producto de un ejercicio de reflexión, puede entenderse como "compuesta" por diferentes "habilidades". En el transcurso del desarrollo profesional, a través de los distintos cursos, justamente de lo que se trata es hacer a los estudiantes responder ante situaciones concretas (por ejemplo evaluaciones), demandándoles hablar como si fueran participantes legitimados de la disciplina, esto es, proponiendo una forma de concebir la situación que dé cuenta de un uso determinado de los conceptos, herramientas analíticas, técnicas, entre otras. De esta manera, el estudiante aprende desde el inicio a movilizar configuraciones, no elementos.

Por otro lado, esto quiere decir que el estudiante no sólo aprende a ser competente cuando se enfrenta a situaciones profesionales, sino también a situaciones propiamente académicas. El estudiante se hace hablante articulada y progresivamente de una multiplicidad de géneros establecidos que se superponen, tensionan, articulan y diferencian entre sí, y que le permitirán ser legitimado en una disciplina determinada.

Dada las características metodológicas, este estudio no pretende ser conclusivo, sino que propone hipótesis que quedan lanzadas para próximas exploraciones. En esta línea, la pregunta que guio esta investigación podría reformularse: ¿cuáles son aquellos géneros discursivos, que según diferentes actores, son nucleares y necesarios para legitimar a un hablante como psicólogo? La pregunta así planteada requiere otra aproximación de estudio con especial énfasis en la descripción de aquellos géneros, esto es, su designación.

Con esta noción de competencia en mente, y distanciándonos de una aproximación de competencias con un énfasis tecnocrático y prescriptivo, es importante recalcar que esta investigación estuvo en función del mejoramiento de la formación en psicología en la Facultad. Como se discutió en los antecedentes, los alumnos que entran a la Universidad Alberto Hurtado no pertenecen a la elite tanto desde un punto de vista de rendimiento en la Prueba de Selección Universitaria, ni en cuanto a sus características socioeconómicas. En este contexto, esta investigación no es un lujo, sino una necesidad. Para asegurar 
que todos los estudiantes que entran a la Facultad, independiente de sus condiciones previas, puedan desarrollarse profesionalmente de manera competitiva (más allá de lo que se hubiera esperado por las condiciones de entrada), es necesario explicitar con claridad qué "competencias" deben ser capaces de desplegar, de manera de poder ver en qué momentos de la formación esas competencias serán promovidas y qué cursos, actividades, experiencias, serán responsables de hacerlo. Tomamos este ejercicio, entonces, como una manera de "ver" las desigualdades en desempeño académico no como desigualdades naturales o de talento, como dirían Bourdieu y Passeron (1964/2003), sino como desventajas sociales de las que hay que hacerse cargo. Un trabajo en esta línea, entonces, no debe verse como burocracia académica, sino como una parte esencial de la educación terciaria en Chile:

"Una pedagogía realmente racional [que va más allá de meros fundamentos psicológicos] debería basarse en el análisis de los costos relativos de las diferentes formas de enseñanza (cursos, trabajos prácticos, seminarios, grupos de estudio) y de los diversos tipos de acción pedagógica (desde el simple consejo técnico hasta la dirección efectiva de los trabajos de los estudiantes); debería tener en cuenta el contenido de la enseñanza o los fines profesionales de la formación y, considerando los diversos tipos de relaciones pedagógicas, no debería olvidar su rendimiento diferente según el origen social de los estudiantes. En cualquier hipótesis, está subordinada al conocimiento que se obtenga de la desigualdad cultural socialmente coordinada, y a la decisión de reducirla" (Bourdieu y Passeron, 2003, p. 111).

\section{Referencias bibliográficas}

Aedo, C. y González, L. E. (2004) La educación superior en Chile. Calidad en la Educación, (21), pp. 61-85.

Aguerrondo, I. (2009) Conocimiento complejo y competencias educativas. UNESCO: IBE working papers on curriculum issues n. ${ }^{\circ} 8$. Disponible en: www.ibe.unesco.org/fileadmin/user_upload/Publications/Working Papers/Lnowledge_compet_ibewpci_8.pdf 
Anaya, G. (1996) College experiences and student learning: The influence of active learning, college environments and cocurricular activities. Journal of College Student Development, (37), pp. 611-622.

Arancibia, V. (1992) Efectividad escolar: un análisis comparado. Estudios Públicos, (47), pp. 101-125.

Astin, A. (1968) Undergraduate achievement and institutional excellence. Science, (161), pp. 661-668.

Asún, R. (2006) Medir la realidad: el sentido de la metodología cuantitativa. En M. Cerón (Ed.) Metodologías de investigación social. Introducción a los oficios. Santiago: LOM Editores.

Bajtín, M. (2002) El problema de los géneros discursivos. En Estética de la Creación Verbal. Buenos Aires: Siglo XXI Editores.

Bartram, D. y Roe, R. (2005) Definition and assessment of competences in the context of the European diploma in Psychology. European Psychologist, 10, (2), pp. 93-102.

Beneitone, P.; Esquetini, C.; Gonzalez, J. et al. (eds.). (2007) Reflexiones y perspectivas de la Educación Superior en América Latina. Informe Final -Proyecto Tuning-América Latina 2004-2007. Bilbao: Publicaciones de la Universidad de Deusto.

Bourdieu, P. y Passeron, J. C. (2003) Los herederos. Los estudiantes y la cultura. Buenos Aires: Siglo XXI. (Publicado originalmente en 1964).

Brunner, J. J. (2009) Educación superior en Chile. Instituciones, mercados y politicas gubernamentales (1967-2007). Santiago: Ediciones Universidad Diego Portales.

Carrasco, A. (2008) Investigación en mejora y calidad escolar: ¿nueva agenda? REICE, Revista iberoamericana sobre calidad, eficacia y cambio en educación, 6, (4), pp. 6-23.

Castro, A. (2004) Las competencias profesionales del psicólogo y las necesidades de perfiles profesionales en los diferentes ámbitos laborales. Interdisciplinaria, 21, (1), pp. 117-152.

SIES (2010) Evolución de la matrícula total por nivel global (1983-2009). Disponible en: http://www.divesup.cl/sies/wp-content/uploads/2010/01/ Evolución-de-la-Matrícula-Total-por-Nivel-Global-1983-2009.xls

Departamento de Psicología, Universidad Católica Raúl Silva Henríquez (2008) Formación Profesional y Especialización. Documento de trabajo no publicado.

Espinoza, Ó. y González, L. E. (2008) Equidad y accesibilidad a la educación superior (1990-2003). En J. J. Brunner y C. Peña (Eds.) Reforma 
a la educación superior en Chile (pp.143-172). Santiago: Ediciones Universidad Diego Portales.

Facultad de Psicología. Universidad Alberto Hurtado. (2007) Informe de Autoevaluación. Documento de trabajo no publicado.

Flowers, L.; Osterlind, S.; Pascarella, E. et al. (2001) How much do students learn in college? Cross-sectional estimates using the college basic academic subjects examination. Journal of Higher Education, 72, (5), pp. 565-583.

García-Huidobro, J. E. (2004) Políticas Educativas y Equidad en Chile. Reflexiones del Seminario Internacional sobre Políticas Públicas y Equidad, octubre, Santiago de Chile.

Goethals, G.; Winston, G. y Zimmerman, D. (1999) Students educating students: The emerging role of peer effects in higher education. Forum futures, pp. 25-45.

González, M.; Gómez, L.; Espinosa, J. C. et al. (2007) Evaluación por competencias de la dimensión ética en la formación de psicólogos en Colombia. Revista Diversitas, Perspectivas en Psicología, 3, (1), pp. $11-24$.

González, J. y Wagenaar, R. (2008) Universities' contribution to the Bologna process. An introduction. España: Publicaciones de la Universidad de Deusto.

Hanushek, E.; Kain, J.; Markman, J. et al. (2003) Does peer ability affects student achievement? Journal of Applied Econometrics, (18), pp. 527544.

James, W. (1995) The principles of psychology. Chicago: Encyclopaedia Britannica. (Publicado originalmente 1980).

Johannert, P.; Masciotra, D.; Barrette, J.; Morel, D. y Mane, Y. (2007) From competence in the curriculum to competence in action. Prospects, vol. XXXVII.

Juliá, M. T. (2006) Competencias profesionales del Psicólogo Educacional: Una tarea asociativa. Revista de Psicología, 15, (2), pp. 115-130.

Knox, W.; Lindsay, P. y Kolb, M. (1993) Doe's college make a difference? Long-term changes in activities and attitudes. Westport, CT: Greenwood Press.

Muñoz, A. L. y Sobrero, V. (2006) Proyecto Tuning en Chile: análisis de procesos de internacionalización de la educación superior. Calidad en la Educación, (24), pp. 247-271.

Murillo, F. J. (2003) Una panorámica de la investigación iberoamericana sobre efectividad escolar. REICE, Revista electrónica iberoamericana sobre 
calidad, eficacia y cambio en educación, 1, (1). Disponible en Nuttal, Desmond; Goldstein, Harvey; Prosser, Robert et al. (1989) Differential school efectiveness. International journal of educational research, 13, (7), pp. 769-776.

OECD (2000). Literacy in the Information Age: Final Report of the International Adult Literacy Survey, Paris and Ottawa: Statistics Canadá.

OECD (2004). Marcos teóricos de PISA 2003: la medida de los conocimientos y destrezas en matemáticas, lectura, ciencias y resolución de problemas. Madrid: Ministerio de Educación y Ciencia, Instituto Nacional de Evaluación del Sistema Evaluativo (INECSE).

OCDE y BIRD/Banco Mundial. La educación superior en Chile. Revisión de políticas nacionales de educación. (2009) Santiago: Ministerio de Educación de Chile. Disponible en: www.divesup.cl/images/archivos/ la-es-en-chile.pdf

Pascarella, E.; Cruce, T.; Umbach, P. et al. (2006) Institutional selectivity and good practices in undergraduate education: How strong is the link? Journal of Higher Education, (77), pp. 251-285.

Perrenoud, P. (1998) La transposition didactique à partir de pratiques: des savoirs aux competences. Revue des sciences de l'éducation, 24 (p. 487514).

Perrenoud, P. (2004) Construire un référentiel de competences pour guider une formation professionnelle. L'Éducateur, pp. 8-11.

Reynolds, D. y Cuttance, P. (Eds.) (1992) School effectiveness. Research, policy and practice. London: Cassell.

Rial, A. (2006) Diseño Curricular por Competencias: El reto de la evaluación. Disponible en: http://www.udg.edu/Portals/49/Docencia\%202010/ Antonio_Rial_(text_complementari).pdf

Rodríguez Ponce, E. (2008) Información y aseguramiento de la calidad de la educación superior. En J. J. Brunner y C. Peña (Eds.) Reforma a la educación superior en Chile (pp. 305-338). Santiago: Ediciones Universidad Diego Portales.

Sanhueza, J. (2008) Modelo de Desarrollo de Competencias en la Formación del Psicólogo. Psicología Organizacional Humana, 1, (1), pp. 145-172.

Sebastian, C. (2007) La diversidad interindividual como una oportunidad para el aprendizaje de los estudiantes de educación superior. Calidad en la Educación, (26), pp. 83-101.

Tobón, S. (2007) El enfoque complejo de las competencias y el diseño curricular por ciclos propedéuticos. Acción Pedagógica, (16), pp. 14-28. 
Toutkoushian, R. y Smart, J. (2001) Do institutional characteristics affect student gains from college? Review of Higher Education, (25), pp. 39-61.

Valenzuela, J. P.; Bellei, C. y de los Ríos, D. (2008) Evolución de la segregación socioeconómica de los estudiantes chilenos y su relación con el financiamiento compartido. Santiago: FONIDE-Ministerio de Educación de Chile.

Zanatta, E. y Moysén, A. (2002) Currículum de la Licenciatura en Psicología, Basado en un Modelo Educativo de Educación Basada en Competencias. Memorias del congreso de la ANUIES: Retos y expectativas de la Educación Superior. Disponible en www.congresoretosyexpectativas. udg.mx/Congreso\%202/Mesa\%201/c)\%20Nuevos\%20modelos\%20 curriculares/1.c.10.pdf

Zimmer, R. y Toma, E. (2000) Peer Effects in Private and Public Schools across Countries. Journal of Policy Analysis and Management, 19(1), pp. 75-92.

Recibido: 15/08/2010

Aceptado: 10/10/2010 